and staff also share in maintaining the house and garden, and provide daily lunches for themselves. Staff members keep each other fully informed about their work, and meet for weekly supervision of their therapy by an external monitor.

Arrangements are made before the course ends for six, weekly one hour group 'bridging' sessions for members who wish to reinforce their new learning and more companionable relationships at home, work and leisure. Longer term group therapy contracts are arranged for members who wish to continue to work together on insufficiently resolved interpersonal problems. Members are also free to contact Tuke House for advice following termination if other resources are temporarily unavailable.

Each therapeutic approach is contained within, and hopefully enriches a broad companionable exploratory and supportive milieu, in which members learn to explore their resistances to therapy, share feelings and problems, reappraise goals, fashion increasingly constructive and confdent self attitudes, and develop more mature and congenial peer group and family relationships.

Three treatment groups proceed through the House each year. The House closes for a few weeks at the end of each group. This allows for staff leave, further training, and the assessment of new referrals. It also prevents the accumulation of long term attenders. Experience suggests that the predetermination of the duration of treatment encourages active participation of members in setting objectives, and also enhances their sense of the value of the treatment.

\section{Evaluation and research}

Priority has been given to evaluation of therapeutic effectiveness and usefulness; the research programme aims at examining the treatments' overall efficacy, elucidating the processes of change, and appraising cost-effectiveness in relation to other treatment approaches. Implicit in this has been the need for refinement of instruments that evaluate process and outcome. Pending the results of this, a consideration of 'consumer satisfaction' is perhaps pertinent. Overall, feedback from group members has been favourable.
Many members express awareness of the 'novelty' of the treatment setting and approach, and a common theme is recognition of the benefits of treatment outside an institutional approach. One member commented "there ought to be a Tuke House at the end of every street".

The experience of staff members is worth commenting on. Working in a new treatment venture inevitably carries many demands due to the uncertainty of an untested and unpiloted area and operating in a multi-disciplinary team also carries its own uncertainties. Apart from developing a new service model, Tuke House has provided a training experience allowing staff members to explore and deal with these kinds of uncertainties. In a way their efforts in this respect have sometimes reflected the group members' experience in treatment. Experience of the staff has so far suggested that a multi-disciplinary approach is particularly apposite and practicable in this community treatment facility.

Tuke House is one model for genuinely communitybased care which initial experience suggests is viable. Its efficacy and cost-effectiveness is yet to be demonstrated.

\section{REFERENCES}

${ }^{1}$ PoweLl, E. (1961) Address to the National Association for Mental Health Annual Conference.

${ }^{2}$ Donovan, C. M. (1982) Problems of psychiatric practice in community mental health centres. American Journal of Psychiatry. $139,456-460$.

${ }^{3}$ CLARE, A. W. (1980) Community mental health centres. Journal of the Royal Society of Medicine, 73, 75-76.

4 JoNEs, K. (1979) Integration or disintegration in the mental health services. Journal of the Royal Society of Medicine, 72, 640-648.

3_ (1982) Scull's Dilemma. British Journal of Psychiatry, 141, 221-226.

'TYrer, P. (1984) Psychiatric clinics in general practice. British Journal of Psychiatry, 45, 9-19.

'Sims, A. C. P., Green, W. J., Hourt, G., May, M. \& Willanes, J. (1985) Tuke House: An experimental community mental health centre for the day treatment of neurotic disorder. British Journal of Clinical \& Social Psychiatry, 3, 67-69.

'YALOM, I. D. (1975) The Theory and Practice of Group Psychotherapy. New York: Basic Books.

\title{
Call for Proposals
}

Proposals for presentation at the 1988 conference of the Association for Death Education and Counselling (ADEC) are now being accepted. The theme is 'Out of the ShadowsInto the Light through Death Education and Counselling' and the conference will be held from 22-24 April 1988 at the Crowne Plaza Hotel, Orlando, Florida. ADEC consists of professionals and lay persons whose goals centre around the promotion of death education, death-related counselling and grief management in educational institutions, residential facilities, churches, community and non-profit making organisations and related settings. Presentations at the Conference will be either research reports, scholarly papers, practice reports/experiential papers or roundtables. Requests must be postmarked no later than 15 December 1987 and notification of acceptance will be made by 15 January 1988. Further information: Dr Darrell Crase, Health Education Division, Memphis State University, Memphis, Tennessee 38152, USA. 